\title{
The Application and Tasks of the Anti-tank Artillery in Combined Arms Combat
}

\author{
FURJÁN Attila ${ }^{1}$
}

\begin{abstract}
Anti-tank is defined as combat against the enemy's tanks and other armoured equipment and vehicles. Its associated tasks include the closing of endangered directions, flanks, and junctions. Anti-tank is the part of combined arms combat which is directed against the tanks grouped for attack or already directly attacking, and the armoured equipment detached to their battle formation. For successful combat, the organization of a solid anti-armour system is required, which includes anti-tank units as a basic element.
\end{abstract}

Keywords: anti-tank artillery, anti-armour, fire capacity, tactical assembly area, deployment area, manoeuvre, battle formation

\section{Introduction}

"Fire support is the collective and coordinated use of target intelligence, indirect laying weapons, armed aircraft, other lethal and nonlethal means and support modes of the battle plan." [1: 33] This definition shows that, according to NATO principles, direct laying anti-tank artillery weapons are not part of fire support. In the armed forces of older NATO member states, anti-tank units belong directly to manoeuvre forces, and their operation is planned and tasks are assigned by the commander and staff of the manoeuvre force.

The activities of anti-tank units forms a part of the anti-armour system; therefore, they do not operate independently but always cooperate with other combined arms units. One of the most important tasks of the Combined Arms Commanders is to organize the anti-armour system, including the planning of the combat operations of anti-tank units.

In the Hungarian Defence Forces, anti-tank units traditionally belong to the artillery. Here some contradiction appears, as direct laying weapons - according to the NATO concept - do not belong to fire support. How shall we interpret that, and how shall we plan and use anti-tank artillery units in practice? After a consultation at the NATO Artillery Working Group session, we were reassured, that in the context of national planning and application, anti-tank artillery forces can be regarded as part of fire support. In case of an operation planned and executed within a NATO formation, the anti-tank artillery forces will be regarded as manoeuvre forces and their application will be planned by the Joint Force Commander and his staff as an anti-tank manoeuvre group. This is a peculiarity we should not be afraid of, as there are other arms peculiarities and differences in several NATO member countries.

1 National University of Public Service, Budapest, Hungary; e-mail: furjan.attila@uni-nke.hu 


\section{Characteristics, Combat Capabilities of Anti-tank Artillery}

\section{Characteristics of Anti-tank Artillery Range}

The range of guided armour-piercing missiles is determined by their maximum distance of launch and the distance of the line of fire - influenced by the terrain in front of their firing positions. Ideally, the range will be the same as the maximum distance of launch.

Example: The maximum distance of launch of the KONKURSZ guided armour-piercing missile combat machine is $4 \mathrm{~km}$.

There is a hill (or a tall forest, row of trees, etc.) in front of the firing position at a distance of $3 \mathrm{~km}$. In that case, the range of the KONKURSZ combat machine will be $3 \mathrm{~km}$.

\section{Fire Capacity}

The fire capacity of the anti-armour artillery is determined by the amount, types and combat effectiveness of its anti-tank assets.

The evaluation of the combat effectiveness of the anti-tank assets is based on the anti-tank equipment type's capability of how many attacking, defending, mobile, fixed, armoured targets - located in a shelter or open area - they are expected to destroy before they would be destroyed, in specified circumstances (attacking, defending, from under shelter or from an open position, etc.).

The combat effectiveness of an anti-tank asset against a given type of armoured target is determined by the following factors, taking into account the mutual counter-actions:

- range (maximum distance of launch, blank range);

- hit probability at a target of a given size (tank, anti-tank asset);

- effectiveness of the projectile (armour penetrating power, destruction zone);

- the probability of destroying the target in case of a hit;

- firing rate;

- protection (in shelter, open area, armoured or non-armoured);

- the type of combat operation (attacking, defending);

- situation (fixed, moving), manoeuvre capability;

- concealment or exposed to reconnoitring;

- preceding in opening fire;

- other factors (e.g. operators' skills, weather-, visibility-, terrain circumstances, etc.). As

the potential to destroy different types of armoured targets is different case by case, artillery professionals have defined a unit of armoured targets, a so-called Tank Unit (TU), for the determination of combat effectiveness.

The TU is a tank having pre-defined characteristics and combat capabilities, the vulnerability of which is used as a baseline to determine the vulnerability of tanks, armoured vehicles, etc. having different combat capabilities.

In the estimations, the tanks that were standardized before 1980 (T-55, T-62, T-72, Leopard-1, etc.) are regarded as equivalent to TU; tanks produced after 1980 (T-80, Leopard-2, Abrams M-1, etc.) are worth 2 TUs; while armoured carriers, infantry combat vehicles, guided armour-piercing missile machines are regarded as $0.7 \times \mathrm{TU}$. 
The indicator of the combat effectiveness of anti-tank assets is the combat-effectiveness factor.

The combat-effectiveness factor (Table 1.) is the measure of how many TUs of armoured targets the anti-tank asset is expected to destroy before it would be destroyed. The values of the combat effectiveness factors differ depending on the type of combat operation, situation of the anti-tank assets and the enemy's armoured equipment, and how these are protected.

Table 1. Combat-effectiveness factor of anti-tank assets. [1: 24]

\begin{tabular}{|c|c|c|c|c|c|c|c|}
\hline \multirow[t]{4}{*}{$\begin{array}{l}\text { Anti-tank } \\
\text { assets }\end{array}$} & \multicolumn{5}{|c|}{$\begin{array}{l}\text { Values of tactical calculations } \\
\text { (in a concrete case) }\end{array}$} & \multicolumn{2}{|c|}{$\begin{array}{c}\text { Medium values } \\
\text { of tactical } \\
\text { calculations }\end{array}$} \\
\hline & \multicolumn{2}{|c|}{ Defending } & \multicolumn{2}{|c|}{ Attacking } & \multirow{3}{*}{$\begin{array}{c}\text { Meeting } \\
\text { engage- } \\
\text { ment } \\
\text { Open }\end{array}$} & Defend- & Attacking \\
\hline & \multicolumn{2}{|c|}{$\begin{array}{l}\text { Own anti-tank } \\
\text { asset, situation }\end{array}$} & \multicolumn{2}{|c|}{$\begin{array}{l}\text { Enemy tanks } \\
\text { situation }\end{array}$} & & \multirow{2}{*}{$\begin{array}{c}\text { Own } \\
\text { anti-tank } \\
\text { assets } \\
\text { situation } \\
\text { Covered } \\
2 / 3 \\
\text { Open } / 1 / 3\end{array}$} & \multirow{2}{*}{$\begin{array}{c}\text { Enemy } \\
\text { tanks } \\
\text { situation } \\
\\
\text { Covered } \\
2 / 3 \\
\text { Open } / 1 / 3\end{array}$} \\
\hline & Covered & Open & Covered & Open & & & \\
\hline SPG-9 & 1.5 & 1.2 & 0.7 & 1.0 & 1.2 & 1.4 & 0.8 \\
\hline $\begin{array}{l}\text { FAGOT, } \\
\text { METISZ }\end{array}$ & 2.0 & 1.5 & 1.0 & 1.3 & 1.5 & 1.8 & 1.1 \\
\hline MALJUTKA & 2.5 & 2.0 & 1.0 & 1.5 & 2.0 & 2.3 & 1.2 \\
\hline KONKURSZ & 2.8 & 2.3 & 1.2 & 1.7 & 2.3 & 2.6 & 1.4 \\
\hline $\begin{array}{l}100 \mathrm{~mm} \text { an- } \\
\text { ti-tank gun }\end{array}$ & 2.0 & 1.5 & 1.0 & 1.3 & 1.5 & 1.8 & 1.1 \\
\hline RPG-7 & 0.3 & 0.2 & - & 0.2 & 0.2 & 0.25 & 0.1 \\
\hline $\begin{array}{l}\text { BMP } \\
\text { (Guided AP M.) }\end{array}$ & 2.0 & 1.5 & 1.0 & 1.3 & 1.5 & 1.8 & 1.1 \\
\hline $\mathrm{T}-55, \mathrm{~T}-62$ & 2.0 & 1.5 & 1.0 & 1.3 & 1.3 & 1.8 & 1.1 \\
\hline $\mathrm{T}-64, \mathrm{~T}-72$ & 2.8 & 2.0 & 1.5 & 1.6 & 1.7 & 2.5 & 1.5 \\
\hline
\end{tabular}

The fire capacity of the antitank artillery (anti-armour capability) can be expressed as the amount of those armoured targets which a given anti-tank group - under normal conditions is expected to be able to destroy during the battle, or the assault of which the group is able to reject in a specific combat situation.

The fire capacity of anti-tank units can be expressed with the following formula:

$F C T U=\sum^{\mathrm{i}} n=1 n i \times C E F i[1: 25]$

where:

FCTU - the fire capacity of the anti-tank unit in TUs; ni - is the number of (i.) type anti-tank assets; CEFi - the combat effectiveness factor of the (i.) type anti-tank asset. 
Example: The fire capacity of a KONKURSZ guided armour-piercing missile battery on the defence, from a prepared deployment area (from shelter).

FCTU $=8$ pcs. KONKURSZ Guided AP Missiles $\times 2.8=22.4 \mathrm{TU}$

The result of this example on the one hand means that a KONKURSZ battery is - theoretically, until the last KONKURSZ combat machine is destroyed - able to destroy 22 TUs of armoured targets from shelter, in case of defence operations, on the other hand that the KONKURSZ battery is able to repulse the assault of an armoured grouping equivalent to 22 TUs with high (90\%) probability and cause a minimum 50\% loss to that group in a specific situation, at a time.

\section{Manoeuvre Capability}

The manoeuvre capability of guided anti-tank missile units is determined by their mobility (movements to firing positions, during manoeuvres to deployment areas), and the time required for the occupation and leaving of deployment areas.

\section{Basic Issues of Anti-Armour Operations}

The attacking party will not distribute their tanks evenly, so it is recommended to group anti-tank units in the main tank-threatened directions. The anti-armour system shall be built up in such a way as to establish coherent and depth-echeloned fire zones in the main tank-threatened directions. Thereby, the continuous destruction of attacking armoured assets will be ensured both in front of the foremost line and in the full depth of defence.

The basis of the anti-armour system is a well-organized anti-tank fire system. To ensure maximum efficiency, a larger part of the anti-tank assets shall be positioned in the vicinity of the front edge so that they inflict as high losses on tanks as possible. In positioning the assets, the commanders shall focus on maintaining continuous fire on tank- and infantry obstacles, as well as ensuring connection of fires between units and the destruction of armoured assets breaking in into the depth.

\section{The Functions and the Basics of Combat Application of Anti-tank Units}

The functions of anti-tank units: to destroy the enemy's tanks, fire weapons, and other armoured assets and combat vehicles, as well as protective installations and the personnel located in those.

Anti-tank units are capable of carrying out fast manoeuvres in endangered directions and deployment areas, with the aim to destroy tanks with medium armour protection and any other types of armoured combat vehicles located there. The fire capacity of anti-tank units depends on the degree of armour protection of the targets, the amount of the involved assets, the skills of operator personnel, the organization of the fire system, the effects of missiles (projectiles) on targets, and the circumstances of the mission.

Let us examine the functions of anti-tank artillery units in the light of the draft anti-armour doctrine: "the Anti-tank Missile Battalion has been integrated into the establishment of the Infantry Brigade for the function of destroying the enemy's tanks, other armoured combat vehicles, and protective installations; as well as close endangered directions, open flanks and 
junctions. Its further tasks include the destruction of armoured assets breaking into the defence and preventing them from gaining ground and providing support on the flanks for own forces' counter-attack. Furthermore, it is applied to destroy low-flying and hovering helicopters. The anti-tank missile battalion is the basic anti-armour fire control and tactical unit of the Infantry Brigade. It is capable of carrying out fast manoeuvres in endangered directions and deployment areas, and performing its basic functions there." [2:1]

The establishment of the battalion have recently been under continuous change; and we also expect modifications to continue, considering the force development aims of all organizational elements of the Hungarian Defence Forces.

In accordance with operational requirements, the establishment of the Anti-tank Missile Battalion includes headquarters and staff - these composing the leadership - and three anti-tank missile batteries and a staff support battery. An anti-tank missile battery is made up of a battery staff and two platoons. Each platoon is equipped by 4-4 pcs. of 9P148 combat vehicles.

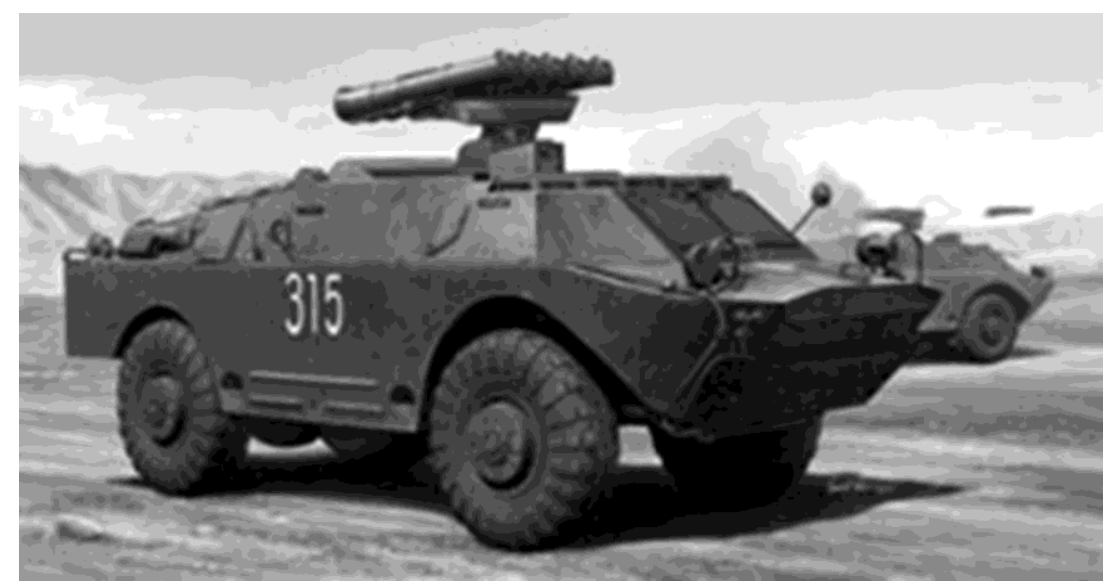

Picture 1. 9 P148 combat machine. [3]

The anti-tank battery is the fire control and tactical unit of the anti-armour artillery. It carries out its tasks either independently or under the command of a higher-level organization.

The artillery platoon is a unit of the anti-armour artillery, which usually carries out its tasks under the command of a Battery, sometimes independently.

The guided armour-piercing missile combat machine and launcher are the fire weapons of the anti-tank unit, which are usually used in combat under the command of a platoon. The personnel directly ensuring the operation of the combat machines and launchers are called the squad or the operating personnel.

\section{The Battle Formation of Anti-tank Units}

The battle formation is the purposeful grouping of forces and assets for the execution of the assigned mission. The battle formation shall ensure the execution of the units' tasks, the full utilization of the units' combat potential, continuous and reliable cooperation and 
connectivity with the superior and other units, the possibility to manoeuvre the unit and the fires, maximum utilization of the opportunities provided by the terrain, and the continuous, uninterrupted command of subordinates.

The battle formation of the anti-tank battery is composed of the battle formations of artillery platoons, the Command (Observation) Post of the Battery Commander, the Armour Observer Post, and the Loading Point.

Upon order by the Brigade Commander, the anti-tank battery can reinforce the anti-tank activities of an infantry battalion, or can operate as an anti-tank manoeuvre unit (anti-tank reserve) under the command of a battery, in case there are more than one tank-threatened directions in the combat area of the brigade.

The anti-tank squads of the support platoons of the infantry company are situated in the battle formation of the company in such a way as defined by the Company Commander.

\section{The Areas and Lines of Anti-tank Units}

Assembly areas, one or two tank-threatened directions, and 2-3 deployment areas per direction are designated for anti-tank units.

The assembly area is the part of the terrain which the anti-tank unit holds or has prepared for occupying. Units are situated in an extended order in the assembly area, in accordance with the expected engagement. "A Battery's assembly area shall be $500 \mathrm{~m}$ wide and $500 \mathrm{~m}$ long." [2: 4-12]

The assembly area shall be designated in the direction of the enemy's expected principal effort (or in the direction of the main attack of own forces) in relation to the deployment area, in such a way that available manoeuvre routes ensure the deployment also in the furthermost areas. The battery must maintain a 15 minute starting notice. On the defence, 1-2 reserve assembly areas can be designated and prepared at a distance of 1-2 km from the assembly area to the side and back. During the attack, the unit takes temporary assembly areas, keeping with the rhythm of the attack. [2: 4-12] The assembly areas shall be named after flowers. 


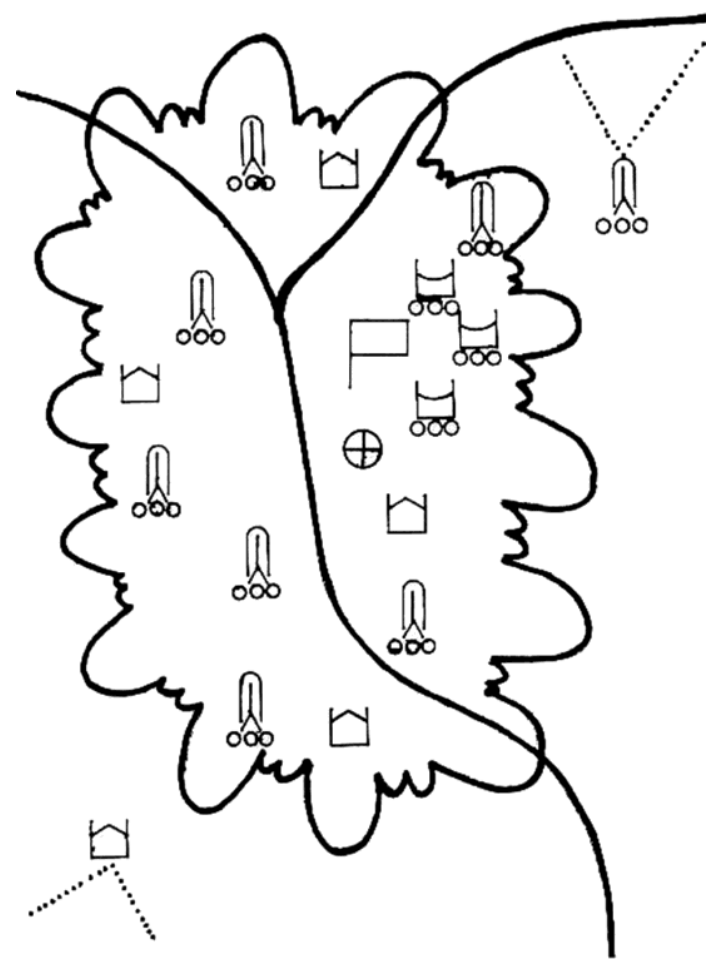

Figure 1. Guided anti-tank missile battery at the assembly area. [2: 4-13]

The anti-tank squads of the support platoons of the infantry company are situated in the readiness area (sheltered area) of the company in such way as defined by the company commander.

The deployment area is the part of the terrain in the tank-threatened direction which is pre-assigned or prepared to be occupied, or which the unit has taken during combat operations in order to destroy the enemy's tanks and armoured combat vehicles. The deployment areas shall be named after mountains and with numbers.

E.g.: "Bakony-2"

This area is the 2. deployment area in the "Bakony" tank-threatened direction.

During the deployment of units into the battle formation on the deployment area, their disposition shall ensure the successful execution of the tasks, mutual connection of fires, transferring of fires from one direction to the other, and all-round defence.

Types of deployment areas:

- planned and prepared deployment area;

- planned, unprepared deployment area;

- unplanned deployment area.

The unit usually takes a planned, prepared deployment area when it is on the defence, and has enough time to inspect the deployment area; thoroughly organize the fire system; practice occupation and leaving of the area, and the fire tasks; and perform the engineering works. In case of a planned, unprepared deployment area, they carry out the inspection of the deploy- 
ment area and the organization of the fire system, but do not have enough time to practice occupation and leaving of the area, and the fire tasks; and perform the engineering works.

The unplanned deployment areas are occupied during combat, when quick changes in the situation compel the commander to use the anti-tank unit quickly, at any place. The occupation of unplanned deployment areas require the unit commander to exercise a high degree of self-reliance and creativity. In this case, the squad commanders' skills and abilities for the tasks are decisive.

"In order to ensure the effectiveness of fire control and fire coordination, the distance in length is 100-200 m between Guided Armour-piercing Missile combat machines, and 300-400 m between the platoons. The dimensions of deployment areas can extend to $2.5 \mathrm{~km}$ in width and $1 \mathrm{~km}$ in length for batteries, $1 \mathrm{~km}$ in width and $500 \mathrm{~m}$ in length for platoons; depending on the combat situation, terrain, and the number of assets involved." [4: 6]

The usual dispositions of units on the deployment area: wedge front (back), echelon right (left), line, or horseshoe formation. These formations usually do not take place clearly by themselves, they are usually applied in combinations, depending on the number of the involved anti-tank assets, the width of the deployment area, and the type of terrain. In today's modern combat, it may happen that only 1-2 assets are actually tasked. The anti-tank squads of the support platoons of the infantry companies operate as ordered by the Company Commander, they have platoon- and squad-level tasks.

\section{Wedge formation:}

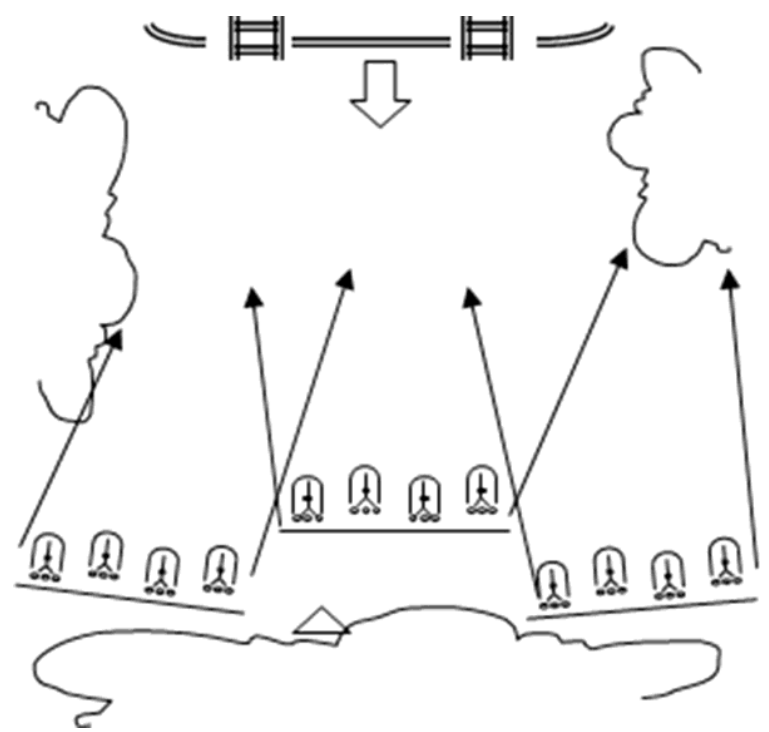

Figure 2. Wedge formation of an anti-tank missile battery (a variant). [4: 6]

This battle formation is recommended if a narrow area must be closed, or if the enemy's battle formation is deeply echeloned. It is advantageous due to the relatively great depth, ensuring the utilization of the maximum fire distance. The disadvantage is that a relatively narrow area can be closed and the units cannot begin firing at the same time. 


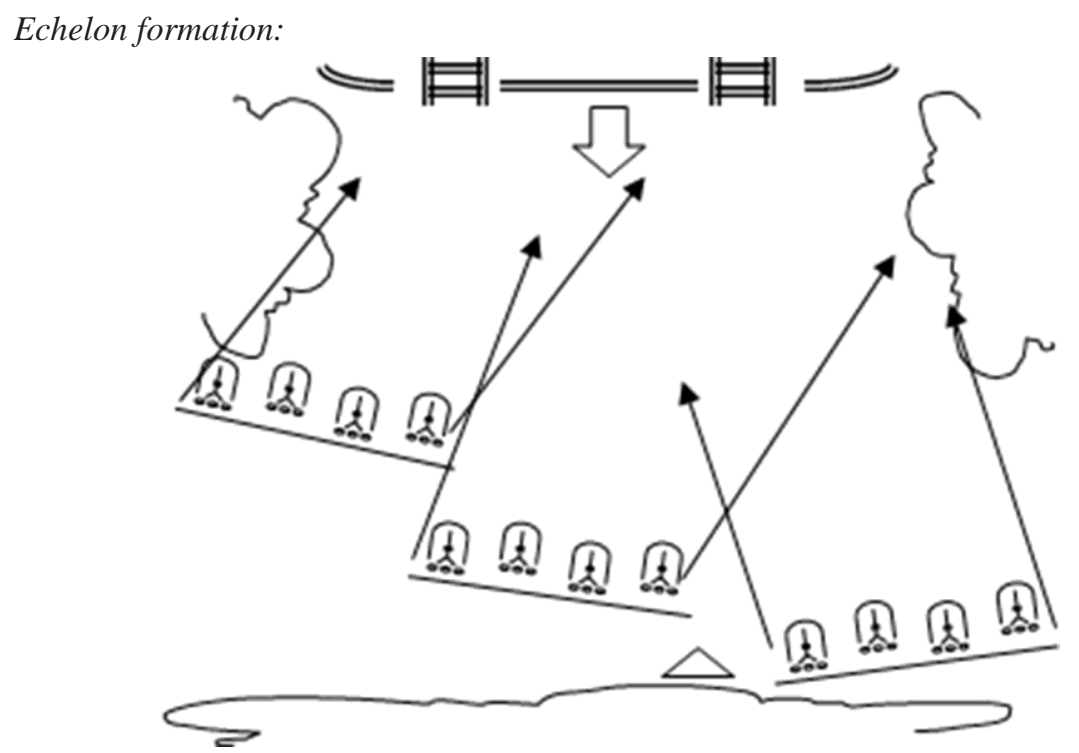

Figure 3. Echelon right formation of an anti-tank missile battery (a variant). [4: 7]

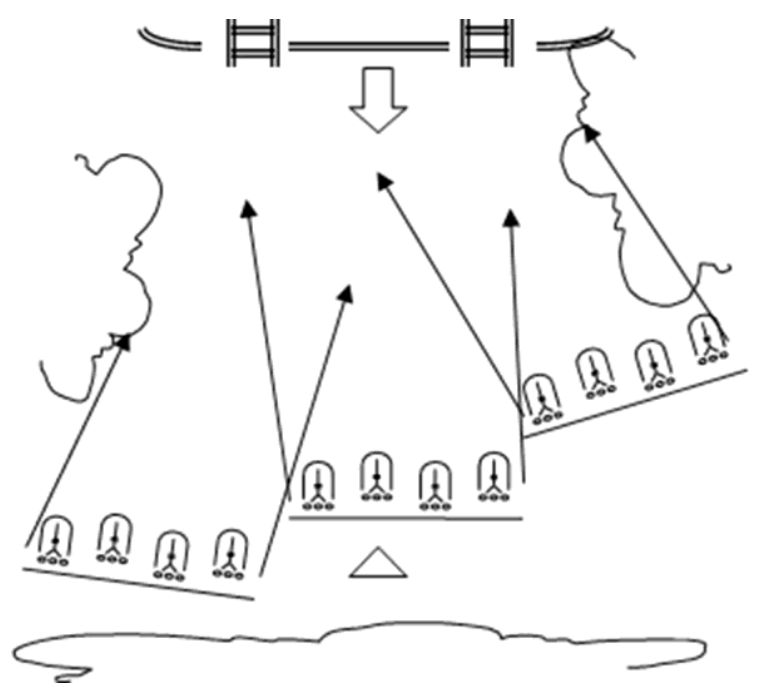

Figure 4. Echelon left formation of an anti-tank missile battery (a variant). [4: 7]

This battle formation is recommended on hilly, mountainous terrain, and on a hill which diagonally crosses the deployment area, because the distance of the hill allows a uniform distance of line of firing for all units.

Its advantage is that opening fire is possible from a large distance, and slant firing can also be conducted. Its disadvantage is that fire can be opened only when the targets have reached the effective range and that is why opening fire simultaneously is not possible, and why the units can close only narrow areas. 


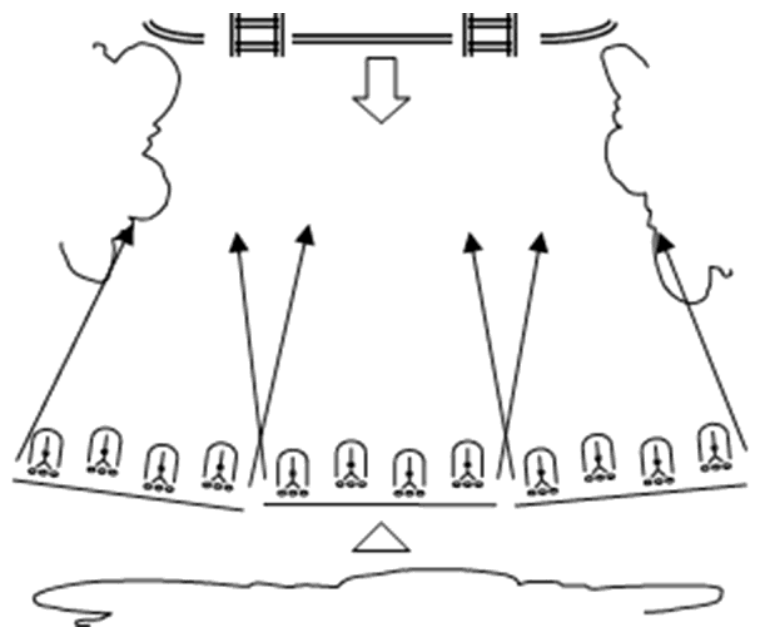

Figure 5. Line formation of an anti-tank missile battery (a variant). [4: 7]

\section{Horseshoe formation:}

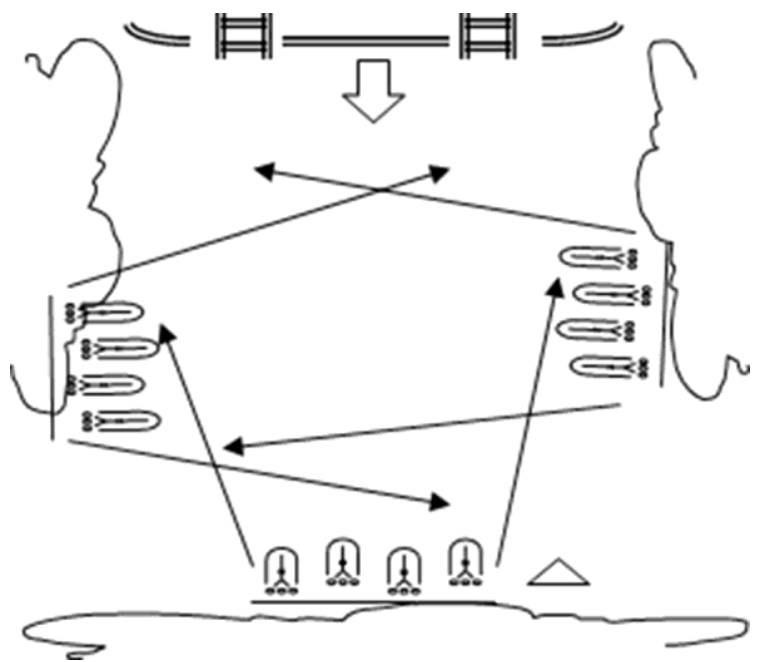

Figure 6. Horseshoe formation of a guided anti-tank missile battery (a variant). [4: 7]

This is the most frequently used battle formation. It provides the possibility for units to deploy to a maximum width and length. It ensures firing at the largest distance, allows the elimination of dead spaces for the weapons, and creates good opportunities for delivering unexpected and high-impact fire.

This battle formation is usually applied for the closing of narrow passages, valleys. The horseshoe formation is in fact an anti-tank pocket of fire. Its advantage is that it allows opening fire simultaneously, and enables fire weapons to fire at the most vulnerable points of tanks. Its disadvantage is the relatively narrow width; and that missed missiles and those which become uncontrollable can cause damage to own forces. 
The Armour Observer Post must be provided with a radar which can reliably detect advancing, deploying tank formations both during day and night, and in fog and under poor visibility conditions. Today, modern defence forces use radars with various performance abilities for the reliable detection of enemy tanks.

The RATAC-S mobile, multi-purpose ground target detection and acquisition radar station is developed and produced by the German ALCATEL SEL AG. The RATAC-S is a coherent-pulse, twin bundle, monopulse Doppler radar, which filters out stationary targets. Its operation is facilitated by a user-friendly menu system, familiar to anyone who uses computers. Its most important functions are:

- radar map can be depicted (mapping indicator mode);

- the radar picture can be stored and any sectors can be zoomed;

- operators can be alarmed in optical and acoustic ways;

- the definition of target coordinates can be refined by freezing the screen;

- GPS can be easily adapted;

- the detection and tracking of the target can be easily documented by the plotter;

- it can independently operate with its own battery unit.

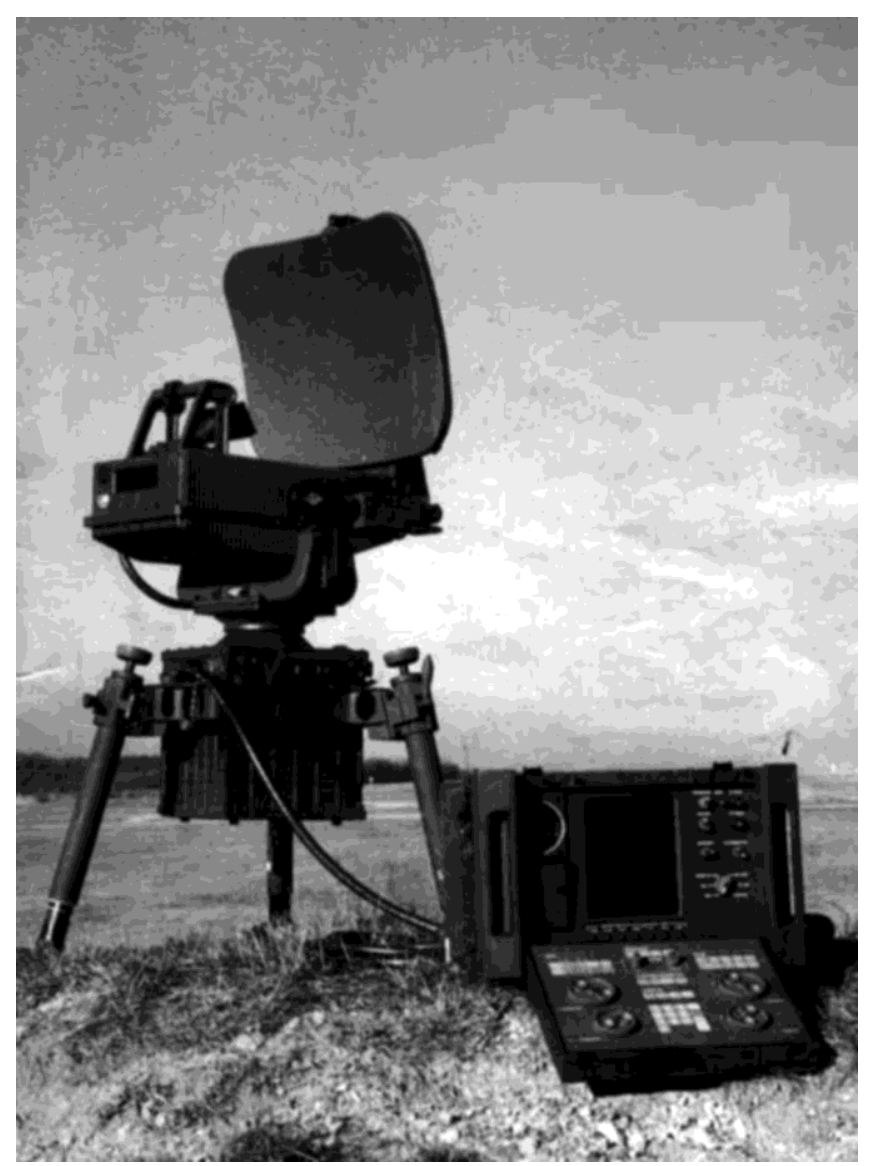

Picture 2. The RATAC reconnaissance radar station, used for the detection and display of enemy tanks and armoured combat vehicles. [5: 75] 
The operator can set the reconnaissance, target tracking, and fire control area from $0^{\circ}$ to $360^{\circ}$ and $0 \mathrm{~km}$ to $38 \mathrm{~km}$ in multiple grades, depending on the task. Sector search can also be set. In that case, the antenna system automatically searches for moving targets in a sector of maximum $110^{\circ}$ width and $20 \mathrm{~km}$ length. Thanks to the sophisticated Doppler technology, the radar can determine even the type of target. Thereby, a soldier, a wheeled or tracked combat vehicle, a train, or rotary wing aircraft can be differentiated.

The RATAC-S is able to maintain detection even in such natural and artificial weatherand atmospheric conditions which restrict visual reconnaissance (e.g. fog, heavy rain, snow, night, smoke, dust).

A controllable, automatic system ensures the filtering of natural background interference - caused by the movement of plants blown by the wind, the waves of the water surface, and changes in the refractive index of the atmosphere. The control unit includes a foldable control panel providing simple, quick and efficient use, a multi-function display unit, a control computer, and a processor for digital signal processing. The control unit is also equipped with a speaker, which emits a sound corresponding to the speed and type of the target being tracked. The control unit can be augmented with further accessories: navigation-, plotter- and video camera device, a headphone instead of the speaker, and elements of connection and the information system.

RATAC-S characteristics: its operating frequency is $9.5 \mathrm{GHz}$, its output of the transmission pulse is $7 \mathrm{~kW}$, its total weight is $125 \mathrm{~kg}$, and its operating temperature range is $32^{\circ} \mathrm{C}$ to $55^{\circ} \mathrm{C}$.

The detection capability of the radar in case of a $90^{\circ}$ detection sector: [5: 76]

- moving people: from $18 \mathrm{~km}$;

- light, wheeled vehicles: from $24 \mathrm{~km}$;

- heavy tracked vehicles: from $30 \mathrm{~km}$;

- helicopters: from $28 \mathrm{~km}$;

- march column: from $38 \mathrm{~km}$.

In case of artillery fire control, the points of burst can be calculated by graphic intersection with an accuracy of $\pm 10 \mathrm{~m}$, which ensures appropriate support for fire control.

\section{The Command of Anti-tank Units}

The command of anti-tank units is the Commanders' activity through which they maintain the combat capabilities of the units, prepare their combat operations, and control the units during the execution of the assigned tasks. The most important element of command is fire control, which covers the reconnaissance of targets, the clarification of firing tasks, taking decisions regarding the firing tasks, assigning firing tasks, the fire manoeuvring activities of units, and the supervision thereof.

The quick and harsh changes of the situation in combined arms combat require the commanders of anti-tank units to exercise continuous, solid, operational and hidden command.

Continuity, permanent influence on the activities of the battery and platoons, which becomes decisive in the critical phases of combat. Its preconditions shall be established during the organization of command. Its main basic factor is the maintaining of uninterrupted communication, on multiple channels. The handover-takeover and if necessary, the immediate takeover of command functions shall be prepared, in case the commander is eliminated. 
Solidness, the pursuit to take decisions in due time and to carry out the defined tasks firmly and tenaciously. To this end, the commander must be familiar with the superior's concept, places and roles of his units in the superior's battle formation and tactics. The commander shall continuously impose high requirements on Subordinates to ensure solidness.

Operationality, the collective enforcement of efficiency, speed, and practicality in the activities of the unit. It is realized through quick reaction to situations and the introduction of measures in a timely manner.

Stealthiness, by keeping all measures taken for the preparation and execution of tasks secret, using encrypted coordinates; and strict compliance with and enforcement of information security regulations.

Unit commanders command their units through oral orders, combat orders, and commands. Squad leaders command their squads by commands and signals. Orders, instructions, commands shall be short and clear.

The unit commander usually organizes the combat in the field. Due to lack of time, tasks must sometimes be clarified during or immediately after establishing the battle formation and its elements. This is the situation in every such case when an unplanned deployment area or a temporary assembly area is to be occupied.

The commander's schedule for organizing the combat depends on the concrete situation, on the assigned task, and on the time available. The preparation of the combat activity starts when the superior's combat order (preliminary combat order) is received, and lasts until the beginning of advancing to battle formation.

Depending on the superior's working method, the commander's working method can be gradual or parallel.

Gradual working method is usually applied at the beginning of organizational work. It is primarily characterized by the sequential work of different command levels, and that tasks are built upon each other.

In case of the parallel method, the command functions are performed upon receiving the superior's order (command), nearly at the same time. The command levels work on the task simultaneously. This method is usually used when the commander has a limited time to organize the activities.

The unit gets prepared for movement in the assembly area on a 10 minute starting notice, positioned in an order corresponding to the battle formation. The commanders prepare their combat control documents related to the given area. Upon order by the superior, the unit starts the march and takes battle formation positions, in accordance with practice training. If there has been no practice training, the squad leader, using terrain coverage, disembarks in the vicinity of the firing position (about $50 \mathrm{~m}$ distance) and controls the combat vehicle into the firing position.

Having taken the firing position, they make combat machines ready for fire, and report to the platoon leader. When the platoon has reached fire readiness, the platoon leader reports that to the battery commander. The battery commander can report about fire readiness to the superior when the battery has reached at least $50 \%$ readiness. After having reached fire readiness, radio silence takes effect. Squad leaders continuously watch their fire sectors until the beginning of fire, and refine their sector sketches if necessary. 


\section{Planning of the manoeuvre of the Guided Anti-tank Battery}

Example: (own source)

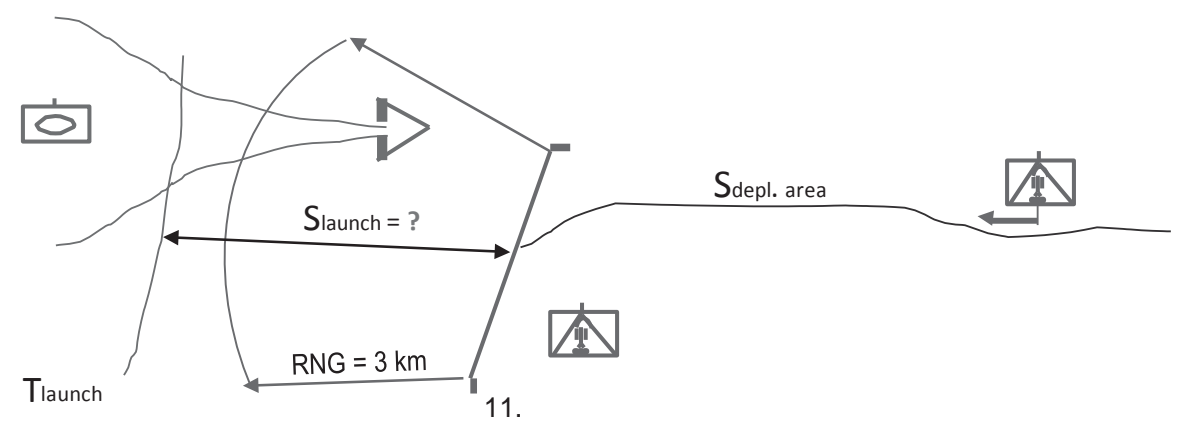

$$
\mathrm{t}_{\text {readyn. }}=\frac{\mathrm{S}_{\text {depl. area }}}{\mathrm{V}_{\text {mnvr. }}} \times 60+\mathrm{t}_{\text {occup. }} \quad \mathrm{S}_{\text {launch }}=\frac{\mathrm{t}_{\text {readyn. }}}{60} \times \mathrm{V}_{\text {tank }}+\mathrm{RNG}
$$

Figure 7. Calculation of a manoeuvre of an anti-tank unit. [6: 57]

Data:

$$
\begin{aligned}
& \mathrm{S}_{\text {depl. area }}=3 \mathrm{~km} \\
& \mathrm{~V}_{\text {mnvr. }}=27 \mathrm{~km} / \mathrm{h} \\
& \mathrm{t}_{\text {occup. }}=4 \mathrm{~min} \\
& \mathrm{RNG}=3 \mathrm{~km} \\
& \mathrm{~V}_{\text {tank }}=10 \mathrm{~km} / \mathrm{h} \\
& \mathrm{t}_{\text {readyn. }}=\frac{3 \mathrm{~km}}{27 \mathrm{~km} / \mathrm{h}} \times 60+4 \mathrm{~min} .=10.67 \sim \underline{11 \mathrm{~min}} \\
& \mathrm{~S}_{\text {launch }}=\frac{11 \mathrm{~min}}{60} \times 10 \mathrm{~km} / \mathrm{h}+3 \mathrm{~km}=\underline{4.83 \mathrm{~km}}
\end{aligned}
$$

The readiness of the anti-tank reserve (anti-tank manoeuvre group) on the designated deployment area means that the units have taken their battle formation, the Commander's Observation Post has been established, the fire system has been organized, that is the antitank reserve is able to begin the destruction of the enemy's armoured assets at the maximum distance of opening fire.

The anti-tank reserve of the brigade usually executes its tasks in cooperation with the mobile closing detachment of the brigade. The area of the mobile closing detachment is situated near the assembly area of the anti-tank reserve, possibly in front of that (in the direction of the deployment areas). 
The mobile closing detachment (three mine-layer platoons with 3 pcs. of PMZ-4 mine- layers per platoon) is able to lay a minefield of $2.4-3.3 \mathrm{~km}$ width (one platoon: $0.8-1.0 \mathrm{~km}$ ) and $30-60 \mathrm{~m}$ length, with one standard load of mines.

The mobile closing detachment lays the minefield - either continuously or fractionally, depending on the terrain and the battle formation - in the front of the area of the anti-tank reserve, at a distance of $0.5-1.0$ of the blank range of anti-tank guns, or 0.5 of the maximum distance of launch of the guided armour-piercing missiles. The mobile closing detachment has to begin the manoeuvre in due time to have 5-10 minutes time advantage over the an- ti-tank reserve on the concrete area.

\section{Conclusions}

The application of anti-tank units shall be planned for the sake of achieving combined arms objectives. As the main striking power of land forces consists in tank troops, the destruction of tank- and other armoured targets is of key importance for the success of combined arms combat. Force superiority applied at the right time and place can settle the outcome of the battle.

Anti-tank units are capable of carrying out fast manoeuvres in the endangered directions and deployment areas, and successfully performing their basic functions there.

\section{References}

[1] FURJÁN A.: The Basics of Fire Support, as well as Combat Use and Command of the Artillery. Budapest: National University of Public Service, 2009.

[2] The Principles of Combat Application of the Anti-tank Missile Batteries, Draft Doctrine. Székesfehérvár: Hungarian Defence Forces Land Force Command, 2005. [3]

www.1999.co.jp/eng/10278975 (downloaded: 1401 2015)

[4] ÖSZ Cs.: The Tasks of Anti-Tank Unit Commanders during the Planning and Commanding of Combat Operations. Székesfehérvár: Hungarian Defence Forces Land Force Command, 2005.

[5] FURJÁN A: Theoretical and Practical Issues of Processing Artillery Intelligence and Intelligence Data in an Integrated Intelligence System in the Hungarian Defence Forces. Budapest: National University of Public Service, 1999. (Ph.D. dissertation)

[6] FURJÁN A.: The Military Use of the Artillery Subunits in Combat Activities of the Infantry Battalion (Company), as well as in Crisis Management and in Peace Support Operations. Budapest: National University of Public Service, 2015. 